\title{
STEREOLOGY AND 3D MICROSCOPY: USEFUL ALTERNATIVES OR COMPETITORS IN THE QUANTITATIVE ANALYSIS OF MICROSTRUCTURES?
}

\author{
HANS ECKART EXNER \\ Department of Physical Metallurgy, Institute of Materials Science, Darmstadt University of Technology, \\ Petersenstrasse 23, D-64287 Darmstadt, Germany \\ e-mail: he.exner@phm.tu-darmstadt.de \\ (Accepted March 24, 2004)
}

\begin{abstract}
With the rapid development of modern techniques for producing 3D images, the assessment of 3D geometry from 2D sections of projections by stereological methods seems to become more and more redundant. The paper aims to show the limits of the two approaches and to outline their relative advantages in practical applications. It is concluded that, for a large variety of applications, classical stereological methods are the most effective way to characterize 3D geometry of irregular microstructures. The basic equations for useful global (field) parameters are summarized and their assessment by manual techniques is indicated. For other types of applications asking for complex parameters like shape, arrangement or size distribution, preference should be given to direct 3D measurements. Parameters obtained by 2D analysis of sections or projections are useful for comparison purposes, for empirical correlation analysis or for fingerprinting-type description. Field and feature parameters and the problems of data reductions are discussed.
\end{abstract}

Keywords: 2D fingerprinting, 3D image analysis, 3D microscopy, basic stereology, effectiveness and limits, materials science, biological applications.

\section{INTRODUCTION}

Many scientific and applied disciplines (as, for example, materials science and technology, biology and bionics, anatomy and medicine, mineralogy and geology) require a qualitative as well as a quantitative understanding of the properties and the behaviour of inorganic and organic materials and their variation during processing, during growth or in use. It has long been realized that, next to chemical composition, the geometry of microstructures is a key to this understanding. In contrast to chemical analysis however, microscopic techniques revealing all relevant details as well as characterization techniques for assessing quantitative geometric parameters are less readily available since there are several principal and experimental obstacles in describing microstructural geometry: Most biological as well as technical materials are made up of a large number of cells, tissues, grains, particles or pores of largely varying size and shape. These components are connected into a continuous three-dimensional body by various types of interfaces. Since most materials are opaque, these one-, two-, and three-dimensional geometric features can not commonly be studied directly with bulk specimens. Microscopic studies require the preparation of cross sections or thin sections, and in order to obtain clear images a high degree of experimental skill is needed. Furthermore, even the qualitative interpretation of these images is not always easy as planar images do not usually display the complexity of the three-dimensional details adequately.

There are three principal approaches to 3D assessment of microstructures: (i) direct viewing and measurements on 3D images accessible by a variety of microscopic techniques using beams penetrating the material under investigation, (ii) reconstruction of spatial geometry from a series of (parallel) sectioning planes, and (iii) stereological methods applying mathematical relationships between $2 \mathrm{D}$ and $3 \mathrm{D}$ geometry. Over the years it has become more and more doubtful to this author if the majority out of the large variety of stereological parameters is really of practical use. Examples where the more sophisticated parameters (like 3D shape and size distributions) have been helpful in finding solutions to problems of practical significance are scarce and, for many parameters suggested in literature, are not existent. 
On the other hand, serial sectioning and stereometry are time consuming and tedious. Therefore, it seems of interest to investigate the effectiveness and limits of the classical stereological approach dating back to the first half of last century, particularly in view of the development and commercialisation of direct 3D imaging techniques.

\section{THE PRESENT STATE OF MICROSTRUCTURAL ANALYSIS}

Quantitative image analysis has met more widespread interest recently than ever before. This is, at least in part, due to the fact that modern microscopic methods (including non-optical methods like atomic force microscopy or other mechanical techniques as well as techniques using spectroscopic signals) employ computers for the formation of images. The information is already available in digitised form. Thus, the assessment of a digital image from analogue input looses its relevance and errors due to improper outlining of the microstructural components (delineation) are reduced by applying the well established procedures based on mathematical morphology (see, for example, Serra, 1982, 1988; Coster and Chermant, 1989; Russ, 1990; Jaehne, 1993; Soille, 1999). These techniques have been implemented in modern instruments reducing a major problem of image analysis.

Sophisticated mathematical procedures like mathematical morphology (Serra, 1982, 1988), fractal analysis (Mandelbrot, 1977, 1983), pattern recognition etc. are also useful for direct assessment of parameters characterising geometry of features in 2D images. For describing microstructures of biological or technical materials, these parameters are sometimes considered superior to the classical stereology approach (outlined for example in the classical works by DeHoff and Rhines, 1968; Underwood, 1970; Saltykov, 1974; Weibel, 1980 and discussed in more detail below). Interesting examples have been published and numerous papers have been discussed showing close correlations between properties and parameters (like "fractal dimension" or "covariance" or other complex mathematical descriptors, see, for example, Coster and Chermant, 1989; Hornbogen, 1989, 1991; Wojnar, 1999). However, as these parameters are rarely used in analytical modelling or numerical simulation, quantitative predictions of such correlations are not available as yet.

In the large majority, these techniques have only been used with 2D images (though principally applicable to $3 \mathrm{D}$ as well). For the identification of microstructural components the results of these techniques may be reliable in spite of the fact that the actual 3D geometry is disregarded. Taken from the procedure of identifying human individuals, this approach has been named "fingerprinting" by one of the author's teachers in this field, H.F. Fischmeister, with the following reasoning: As even the most exact quantitative evaluation of a fingerprint does not include any information on the individual's size or eye colour, 2D image analysis is able to yield an exact identification of a structure without any direct relationship to its properties or origin. However, to my personal opinion, the use of 2D parameters does not contribute much insight into the physical or biological background of the influence of processing parameters on 3D geometry of microstructural features and its effect on the properties and the function of materials, and thus has not helped much to solve problems of practical or theoretical significance.

Direct measurement of three-dimensional descriptors by serial sectioning or stereometry has developed slowly and has been applied rarely. Procedures for assessing 3D coordinates from the parallaxe in two pictures of the same image region obtained by tilting the sample were worked out for manual and automatic procedures (see, for example, Bauer and Exner, 1981; Exner, 1988, 1996, 2001; Stampfl et al., 1996, among others). As these procedures are rather tedious as well, only a few (but fundamentally or practically significant) applications have been published which demonstrated the potential of direct assessment of 3D characteristics. With the more recent upcoming of automated 3D microscopy employing computer controlled image formation and computer-aided image assessment (covering the length scales from atoms to meters) a new era of 3D image analysis is opening. Commercial instruments based on well known or newly developed physical principles become available at a rapid rate and, as usual for electronic systems, rapidly decreasing prices. In the following some of these instruments will be briefly discussed with respect to their ability to give quantitative information on $3 \mathrm{D}$ geometries of structures.

\section{DIRECT ASSESSMENT OF 3D MICROSTRUCTURES}

Classical light microscopy has two principal disadvantages for 3D viewing: the low depth of focus and the opaqueness of most materials. In confocal light microscopy (see, for example, Wilson, 1990, or Pohl, 2002), the narrow focus is employed advantageously for getting 3D images of surfaces: A highly focussed laser beam is used to create sharp pictures of regions of identical height by eliminating all stray light from 
other regions. The beam scans the sample in height and the resulting pictures are combined to a spatial image. As the xyz coordinates are easily available, the coordinates of any feature of interest can be assessed with high lateral and height resolution (approx. 0.3 and $0.4 \mu \mathrm{m}$ respectively). The CLSM (Confocal Laser Scanning Microscope) must be considered to become a routine instrument for the qualitative and quantitative analysis of rough surfaces (in spite of the presently rather high price of instruments which are commercially available for example from Leica Scientific Instruments, Wetzlar, Germany, or Atos GmbH, Pfungstadt, Germany). A number of interesting applications have been published up to date (see, for example, Pohl, 2002), and many more can be anticipated.

Mechanical scanning of surfaces can be done at low resolutions by mechanical stages (profilometers). A diamond tip is used to scan the surface and parallel profiles are combined to form a 3D picture. The danger of damaging the surface, the rather low speed and the problem to reach fine narrow surface details limit the application of mechanical stages like the well known Hommel Tester. Nevertheless this technique is widely used, for example for quantitative assessing the surface topography of machined metal parts or of fracture surfaces.

On the other end of the length scale, scanning probe microscopy (SPM) like atomic force microscopy and scanning tunnelling microscopy allow the quantitative measurement of 3D coordinates of finest details as atom positions, surface structure of thin films, size, shape and distance of nanometer particles and microwear surface roughness (see, for example, Exner, 1996; Durst and Goeken, 2001; Schliffmann, 2002).

A comprehensive overview and comparison of microscopic techniques used in fractography was recently published (Materna-Morris et al., 2003). Most of these techniques are limited to surfaces. Analysis of microstructures inside bulk specimens is possible only if the scanning probe is able to penetrate the material. A classical method is transmission electron microscopy (TEM) which, with tilted images, can provide $3 \mathrm{D}$ data at high resolution. Little use was made of this technique as quantitative image analysis has rarely been employed with TEM images.

High-resolution computer X-ray tomography (HRXCT) is a new and most promising method, which has recently been developed (see, for example, Maire et al., 2002; Sauerwein, 2003). Since some time, radiographic tomography has been used successfully in medicine to obtain images of the interior of the human body. The spatial resolution of instruments using line scanners (2D tomography) was not compatible with that required for materials investigations. At present, high-resolution microtomography is under rapid development. Using synchrotron radiation, the high intensity of a monochromatic parallel beam increases the resolution power to less than $1 \mu \mathrm{m}$, and the high energy of the beam (beyond $100 \mathrm{keV}$ ) makes it possible to penetrate materials with high atomic numbers (Baruchel et al., 2000, Maire et al., 2002). Some interesting applications of synchrotron based high-resolution tomography for qualitative inspection of the interior of materials (aluminium and polystyrene foam, composite materials and metal alloys) as well as quantitative assessment of 3D microstructures (ceramic grain structures, size distribution and shape of particles and in-situ investigation of damage in SiC-Al metal matrix composites) have been reviewed recently (Maire et al., 2002).

As synchrotrons are not readily available, a new generation of X-ray computer tomographs based on high-intensity X-ray sources and 2D detectors is of high interest. An example of a commercial instrument is shown in Fig. 1. The X-ray beam penetrates the sample, which is positioned on the rotating stage. As in 2D tomography, defects like pores and interfaces give the contrast. Scanning is done along the rotary axis using a planar detector. Signals coming from a narrow region are accumulated while signals from other regions are eliminated by the computer. In this way, the focus is narrow and the resolution is increased dramatically. With resolution limits of presently a few micrometers and the perspective to reach a few tenth of a micrometer and with prices in the order of 30.000 to 150.000 US\$ (with the perspective of a significant drop with increasing number of commercial devices) this technique will soon find widespread application.

Biological samples have been looked at for some time with excellent results owing to the fact that Xrays penetrate substances containing only light elements. An example is shown in Fig. 2. Recently, metallic and ceramic materials (mostly consisting of elements with rather low atomic numbers like aluminium) have been successfully investigated. A demonstration of the images produced is shown in Fig. 3: The porosity of cast metal pieces can be assessed without sectioning the sample yielding the size, shape and spatial distribution of the casting defects. Virtual (destruction free) sections can routinely be made and investigated like actual sections but with a dramatic decrease of experimental effort, i.e., serial sectioning can be widely replaced by computer- 
generated images of sections in different orientations. As the 3D coordinates are available, all the classical measuring techniques and parameters are readily accessible. 2D image analysis procedures were adopted for 3D analysis (see, for example Decker, Jeulin and Tovena, 1998, Conan et al., 1992, Gratin 1993 or Delarue and Jeulin, 2003). It is anticipated that, with special software packages becoming available, parameters offered by mathematical morphology will be applied in 3D more frequently, yielding much more relevant information as that obtained by the usual 2D point processing procedures. For example, by opening and closing operations 3D size distributions, distributions of particle distances or particle shapes, among other useful feature parameters, can be measured directly with much more reliability as by stereological 2D-3D conversion procedures.

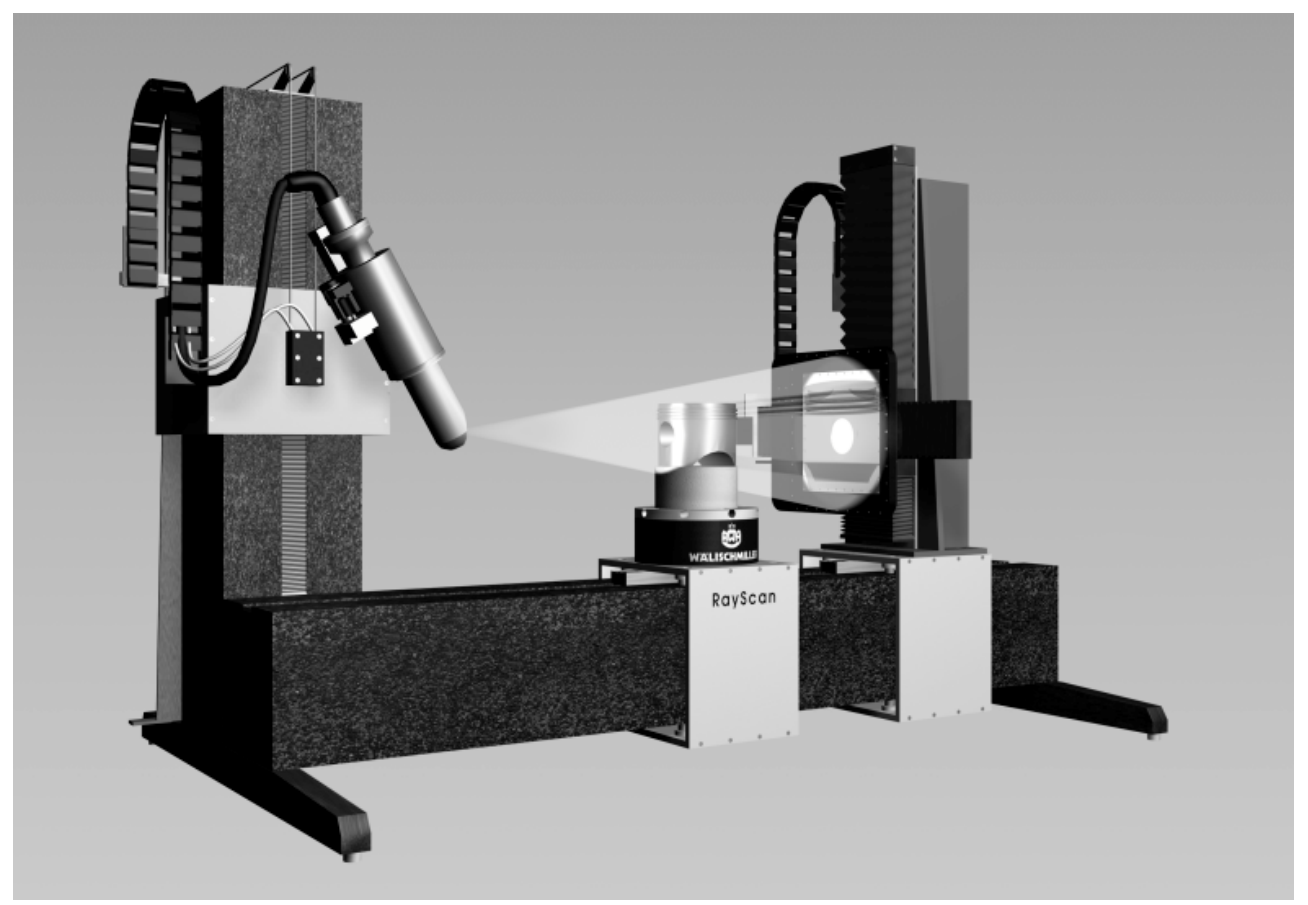

Fig. 1. Schematic view of a commercial high resolution X-ray tomograph (courtesy Hans Waelischmiller GmbH).

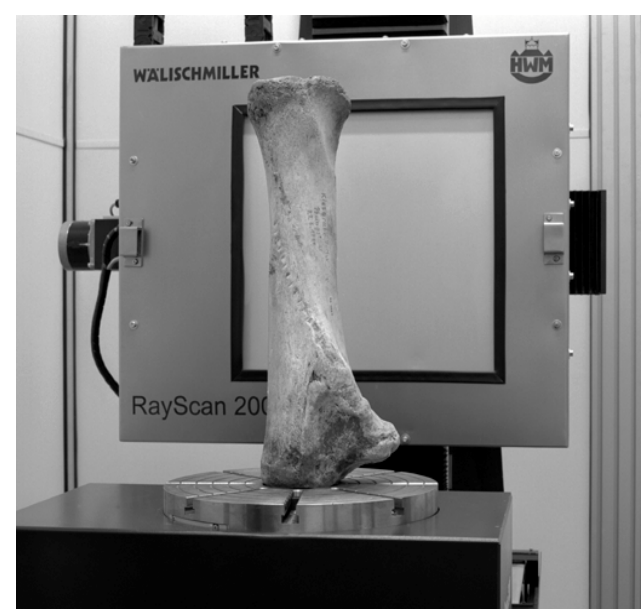

a)

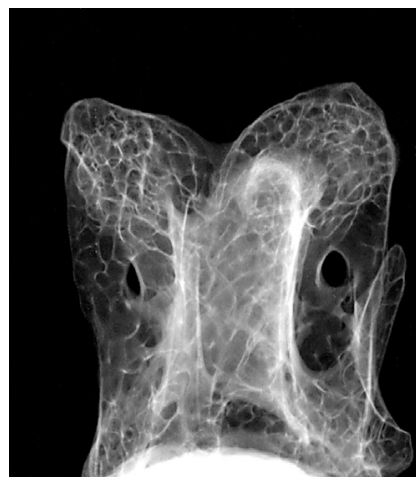

b)

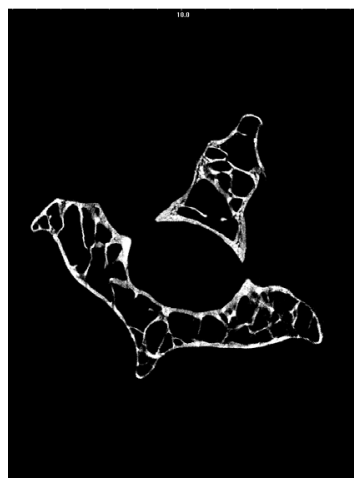

c)

Fig. 2. Bone of a paleontologic dwarf elefant (courtesy Hans Waelischmiller GmbH). a) setup in the tomograph chamber; b) virtual longitudinal section; c) virtual cross section. 


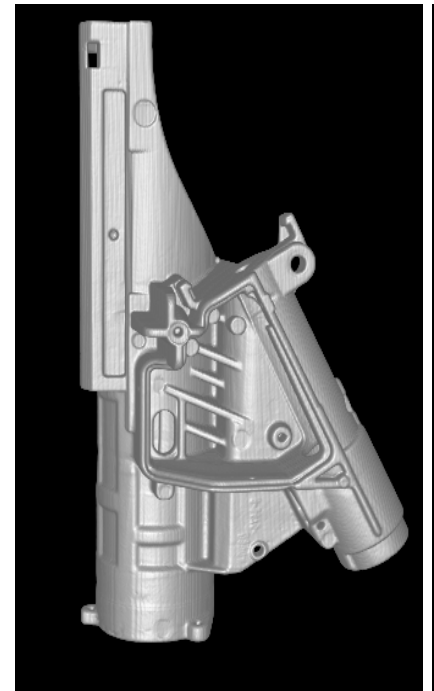

a)

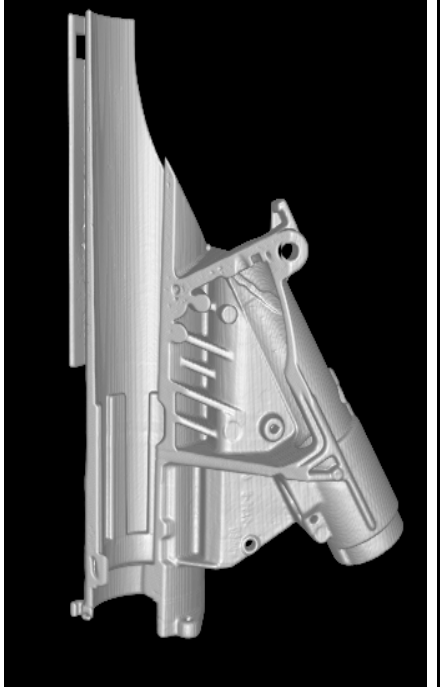

b)

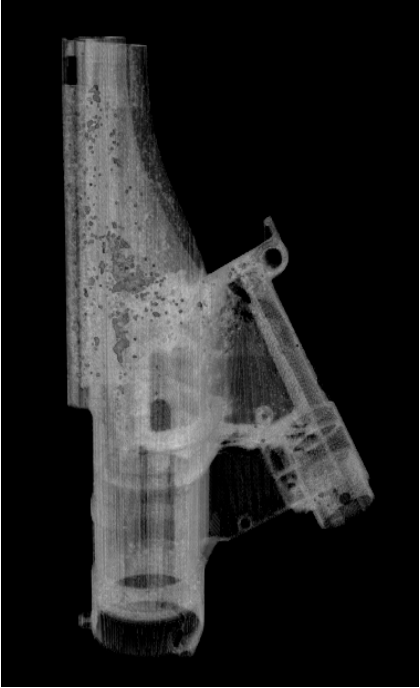

c)

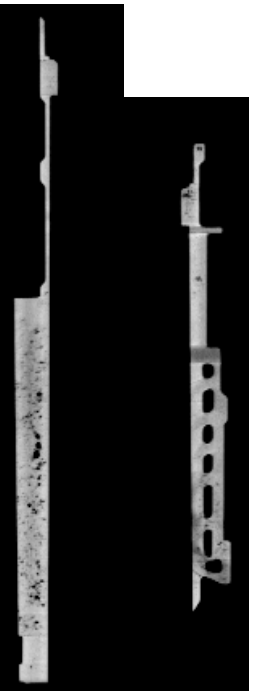

d)

Fig. 3. Aluminium cast part (courtesy Hans Waelischmiller GmbH). a) 3D view; b) partial section, c) semitransparent $3 D$ view with porosity distribution; d) virtual longitudinal sections.

\section{STEREOLOGY}

The scope of stereology (originally meaning "knowledge of space") has been discussed by scientists of many disciplines over the years. The International Society for Stereology has tried to standardize the terminology as well as the nomenclature (see, for example, Underwood, 1970; Weibel, 1980; Exner, 1987) however with limited success. The accepted but rather narrow definition by Underwood (1970) reads " Stereology is the body of methods for the investigation of three-dimensional space when only two-dimensional sections through solid bodies or their projections on a surface are available". Thus, image analysis, microscopy and other types of image acquisition, metallographic techniques etc. are seen as neighbouring fields but not as subgroups of stereology. Here we define stereology as the method to derive a quantitative description of three-dimensional geometry from data obtained by quantitative image analysis of two-dimensional images and its application to microstructures. For the development of stereology, its achievements, techniques and applications, classical textbooks (for example, DeHoff and Rhines, 1968; Underwood, 1970; Saltykov, 1974; Weibel, 1980) should be consulted in addition to more recent books and reviews (for example, Rhines, 1986; Russ, 1986; Exner and Hougardy, 1988; Coster and Chermant, 1989; Exner, 1994, 1996; Exner and Rettenmayr, 1996; Wojnar, 1999; Ohser and Muecklich; 2000; Ohser, 2001).

There are two ways to describe the threedimensional geometry of microstructures by stereological techniques: One is to take measurements on a large number of two-dimensional features (grains, particles, pores, etc.) and to find ways to convert these twodimensional measurements into three-dimensional distributions of specific characteristics (size, shape, curvature, etc.). This conversion requires usually unrealistic approximations (e.g., the assumption of exact spherical shape for the conversion of planar to spatial size distributions). Frequently, from the information contained in these distributions only the average (mean value) is taken. Averaging is sensitive to the variable used. For example, this results in different values of average particle size if the mean of the number frequency or that of volume frequency is used.

The development of stereological relationships as well as parameters for describing microstructural geometry has been overwhelming. It appears that the number of proposals for geometric characteristics and experimental procedures is higher than the number of scientific and technical problems which stereology and quantitative microscopy have managed to solve. The uncritical habit to publish solutions to problems which do not exist (Hilliard, 1972) has been followed up by another generation of stereologists and image analysis specialists. This created a big problem for those who want to apply stereology in practice as the distinction between useful and redundant techniques is not obvious.

The second way for applying stereology to practical problems (advocated by many prominent scientists and by the present author), is to describe the microstructure by a set of so called "global parameters" This term was coined by F. N. Rhines who developed this concept and called it "microstructology" (Rhines, 
1986). The data for determining the most relevant global parameters are derived from counting measurements performed on two-dimensional crosssections using stereological equations (though automatic image analysis may help to speed up measurements and to improve the statistical precision). The strength and generality of these equations (which have the status of mean value theorems in statistics) are based on the fact that no geometric assumptions are necessary for their derivation. The only requirement for their validity is that the properties of the entire population of microstructural features in the specimen to be characterized are contained in the test sample. This may be difficult to achieve as the microscopic image only views a very small sample area and the information has to be extrapolated to features like organs or machine parts which usually are orders of magnitude larger than the field of microscopic investigation.

However, if the test sample is representative for the specimen and properly described, each of the global parameters provides an unbiased estimate of a specific geometric characteristic of the entire microstructure. As pointed out by Rhines (1986), each global parameter is a simple (normalized) sum and, irrespective of the mixture of shapes, sizes and mutual arrangement of grains, particles, pores, cells etc., can be expressed by a simple value without reference to other parameters. The global parameters provide an accurate, though limited, description of the three-dimensional geometry of real microstructures. Their decisive advantage is that they define those quantities which can be directly related to the properties and functions of a material by physical reasoning. The two most useful global parameters are without any doubt volume fraction and interface densities. In principle, counting of points using a graticule with points and/or straight lines is fully adequate to assess volume fractions and interface densities. With these few basic data, mean size, mean spacing, orientation, neighbourhood and connectivity can be quantitatively described by simple and easily comprehensible equations relating $2 \mathrm{D}$ measurements to $3 \mathrm{D}$ quantities (Table 1). All these parameters can be calculated from data obtained with planar images without any assumption but randomness of sampling. The procedures for the assessment of these global parameters are described in classical textbooks (De Hoff and Rhines, 1968; Underwood; 1970; Weibel, 1980) as well as in more recent compilations (Rhines, 1986; Exner, 1992, 1994; Ohser, 2001). Detailed prescriptions of standard counting procedures for single-, two- and three-component microstructures with worked examples using synthetic pictures (reproduced in Figs. 4 and 5) can be found in Exner (1992).

Table 1a and b. Important global parameters derived from measurements on planar cross sections. Subscripts $V$, $A$ and $L$ indicate that the quantities refer to unit volume of the structure, to unit area of the cross section or unit length of the test line respectively. Subscript $P$ indicates normalisation to the number of test points used in point sampling. Note that all parameters defined in the table can be determined from measurements in representative cross sections without any further assumptions.

Table 1a. Important global parameters for single - component materials.

\begin{tabular}{lll}
\hline $\begin{array}{l}\text { Global 3D parameter and } \\
\text { stereologic relationship }\end{array}$ & Examples of applications & $\begin{array}{l}\text { Related 2D quantity } \\
\text { on cross section }\end{array}$ \\
\hline $\begin{array}{l}\text { Boundary density, } S_{V} \\
S_{V}=2 P_{L}\end{array}$ & $\begin{array}{l}\text { Grain boundary area, } \\
\text { Cell boundary area }\end{array}$ & $\begin{array}{l}\text { Number of intersection points of } \\
\text { boundary with test line, } P_{L}\end{array}$ \\
$\begin{array}{l}\text { Mean linear size, } \overline{\mathrm{L}} \\
\overline{\mathrm{L}}=1 / P_{L}=2 / S_{V}\end{array}$ & $\begin{array}{l}\text { Mean linear grain size, } \\
\text { Mean linear cell size }\end{array}$ & $\begin{array}{l}\text { Number of intersection points of } \\
\text { boundary with test line, } P_{L}\end{array}$ \\
$\begin{array}{l}\text { Degree of orientation, } F_{(o r)} \\
F_{(o r)}=2 P_{L(o r)} /\left(P_{L(o r)}+P_{L(p e r p)}\right) \\
=S_{V(o r)} / S_{V(t o t)}\end{array}$ & $\begin{array}{l}\text { Oriented fraction, } S_{V(o r)}, \text { of } \\
\text { total (isotropic and oriented) } \\
\text { interfaces, } S_{V(t o t)} \text {, in drawn or } \\
\text { extruded materials, tree cells }\end{array}$ & $\begin{array}{l}\text { Number of intersection points with } \\
\text { test lines oriented in and } \\
\text { perpendicular to orientation } \\
\text { directions, } P_{L(o r)} \text { and } P_{L(p e r p)}\end{array}$ \\
\hline
\end{tabular}


Table 1b. Important global parameters for two - component materials.

\begin{tabular}{|c|c|c|}
\hline $\begin{array}{l}\text { Global 3D parameter and } \\
\text { stereologic relationship }\end{array}$ & Examples of applications & $\begin{array}{l}\text { Related 2D quantity } \\
\text { on cross section }\end{array}$ \\
\hline $\begin{array}{l}\text { Volume fraction, } V_{V} \\
V_{V}=A_{A}=L_{L}=P_{P}\end{array}$ & $\begin{array}{l}\text { Fractions of components, } \\
\text { materials density }\end{array}$ & $\begin{array}{l}\text { Area fraction, } A_{A} \\
\text { Line fraction, } L_{L} \\
\text { Point fraction, } P_{P}\end{array}$ \\
\hline $\begin{array}{l}\text { Interface density } \\
S_{V}=2 P_{L}\end{array}$ & $\begin{array}{l}\text { Interface area between phases } \\
\text { or components, } \\
\text { pore - solid interface }\end{array}$ & $\begin{array}{l}\text { Number of intersection points } \\
\text { between interface and test line, } P_{L}\end{array}$ \\
\hline $\begin{array}{l}\text { Mean linear size, } \overline{\mathrm{L}} \\
\overline{\mathrm{L}}=P_{P} / P_{L}=2 V_{V} / S_{V}\end{array}$ & $\begin{array}{l}\text { Mean particle size, } \\
\text { Mean cell size, } \\
\text { Mean pore size, }\end{array}$ & $\begin{array}{l}\text { Point fraction, } P_{P} \text {, number of } \\
\text { intersection points between interface } \\
\text { and test line, } P_{L}\end{array}$ \\
\hline $\begin{array}{l}\text { Mean linear distance } \\
\overline{\mathrm{D}}=\left(1-P_{P}\right) / P_{L}=2\left(1-V_{V}\right) / S_{V}\end{array}$ & $\begin{array}{l}\text { Mean linear distance (mean } \\
\text { free path) between particles, } \\
\text { cells, pores, etc. }\end{array}$ & $\begin{array}{l}P_{P} \text { and } P_{L} \\
\text { see mean linear size }\end{array}$ \\
\hline $\begin{array}{l}\text { Contiguity, } C^{\alpha \alpha} \\
\begin{aligned} C^{\alpha \alpha} & =P_{L(\alpha \alpha)} /\left(P_{L(\alpha \beta)}+P_{L(\alpha \alpha)}\right) \\
& =S_{V(\alpha \alpha)} / S_{V(t o t)}\end{aligned}\end{array}$ & $\begin{array}{l}\text { Fraction of spatial area shared } \\
\text { with other grains of } \\
\text { component } \alpha \text { connectiveness }\end{array}$ & $\begin{array}{l}\text { Number of intersection points of test } \\
\text { lines with grain }(\alpha \alpha) \text { boundaries, } \\
P_{L(\alpha \alpha)} \text {, and with }(\alpha \beta) \text { interface, } P_{L(\alpha \beta)}\end{array}$ \\
\hline $\begin{array}{l}\text { Neighbourhood, } C^{\alpha \beta} \\
\begin{array}{l}C^{\alpha \beta}=P_{L(\alpha \beta)} /\left(P_{L(\alpha \beta)}+P_{L(\alpha \alpha)}\right) \\
\quad=S_{V(\alpha \beta)} / S_{V(t o t)}\end{array}\end{array}$ & $\begin{array}{l}\text { Fraction of interface shared by } \\
\text { components } \alpha \text { and } \beta \\
\text { connectivity of different } \\
\text { components }\end{array}$ & $\begin{array}{l}P_{L(\alpha \beta)} \text { and } P_{L(\alpha \alpha)} \\
\text { see contiguity }\end{array}$ \\
\hline $\begin{array}{l}\text { Degree of orientation, } F_{(o r)} \\
F_{(o r)}=2 P_{L(o r)} /\left(P_{L(o r)}+P_{L(p e r p)}\right) \\
\quad=S_{V(o r)} / S_{V(t o t)}\end{array}$ & $\begin{array}{l}\text { As for single component } \\
\text { materials, for directionally } \\
\text { cast structures, oriented } \\
\text { structures in plants or tissues }\end{array}$ & $\begin{array}{l}\text { Number of intersection points with } \\
\text { test lines oriented in and } \\
\text { perpendicular to orientation } \\
\text { directions, } P_{L(o r)} \text { and } P_{L(\text { perp })}\end{array}$ \\
\hline
\end{tabular}

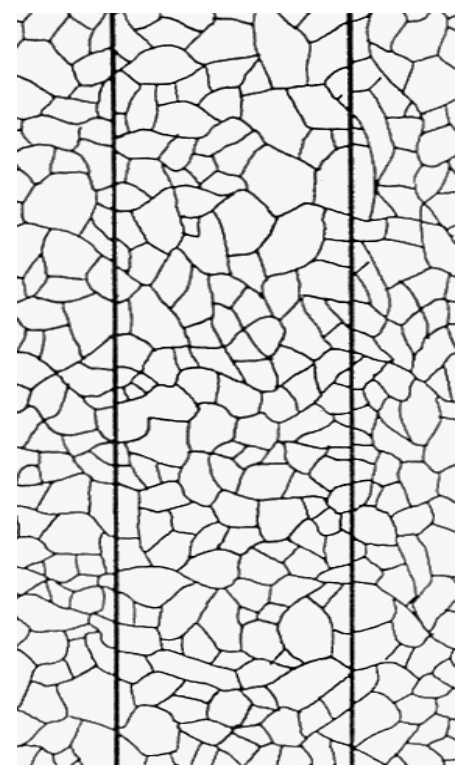

a)

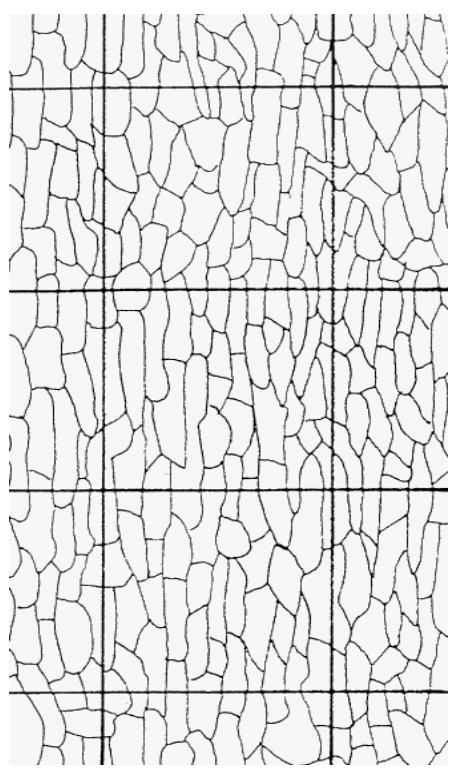

b)

Fig. 4. Counting procedures for determining global stereological parameters in single-component microstructures. a) isotropic grain structure, counting of number of intersection points of boundary with test line, $\left.P_{L} ; b\right)$ oriented grain structure, counting of number of intersection points with test lines oriented in and perpendicular to orientation directions, $P_{L(o r)}$ and $P_{L(p e r p) \text {. }}$ 


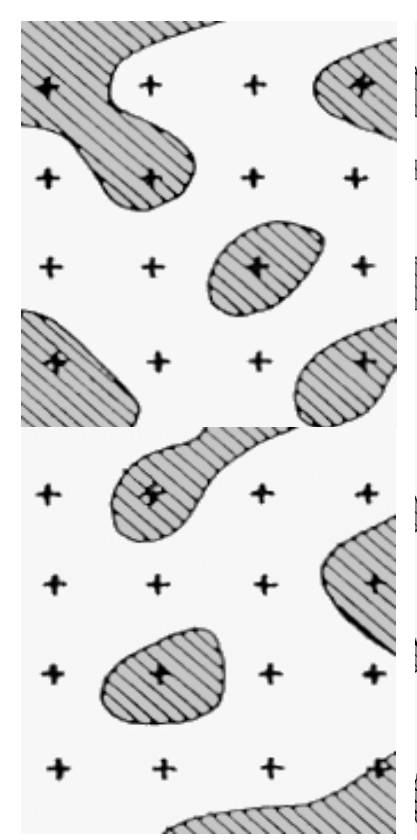

a)

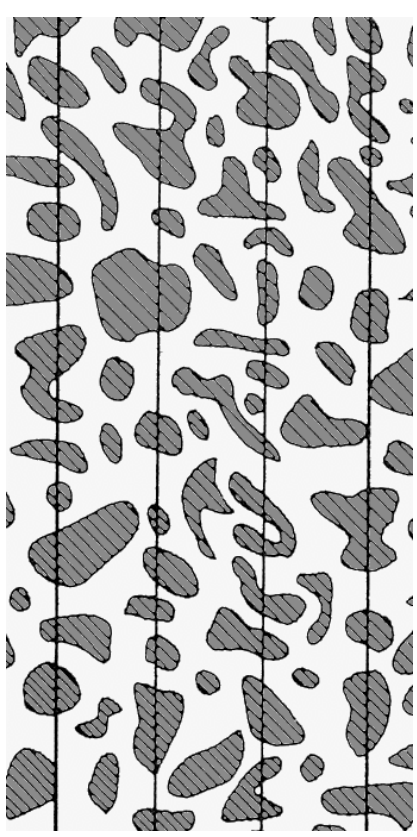

b)

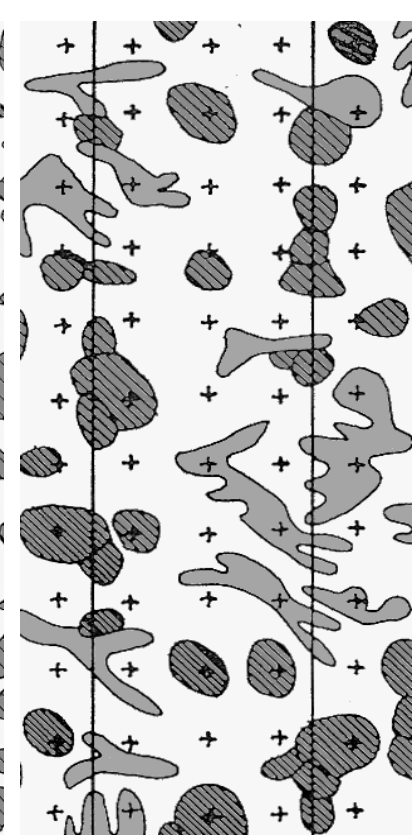

c)

Fig. 5. Counting procedures for determining global stereological parameters in two- and multi-component microstructures. a) counting hit points with a point grid in two fields for determining the volume fraction; $b$ ) counting the number of intersection points of test lines with $\alpha \beta$-interface, $P_{L(\alpha \beta)}$; c) counting of the number of intersection points of test lines with grain $(\alpha \alpha)$ boundaries, $P_{L(\alpha \alpha)}$, and with $\alpha \beta$-and $\alpha \gamma$-interfaces, $P_{L(\alpha \beta)}$ and $P_{L(\alpha \gamma)}$ in a three-component microstructure.

\section{STEREOLOGY OR 3D MICROSCOPY?}

From what has been said above, neither stereology nor 3D microscopy offer ideal solutions for all practical cases. It is strongly advocated to use the global stereological parameters with the following exceptions: (i) the microstructure is not statistically homogeneous, i.e., it is varying locally in a systematic way, (ii) information on individual features is needed, or (iii) the problem under investigation asks specifically for other parameters.

Volume fraction and interface densities should be considered in the first place whenever average amount, size or one of the other quantities derived from interface densities summarized in Table 1 describe the microstructure for the problem under investigation. There are numerous cases of scientific as well as practical examples where this has been the case. To this author's experience, one parameter (mean linear grain/cell size or grain/cell boundary density) and two parameters (volume fraction and size or interface density) are fully adequate to deal with the vast majority of all practical problems in materials science and technology. Such practical problems range as widely as following up microstructural changes during heat treatment or during the life cycle of materials, comparing the as produced microstructure with that requested, or correlating properties to microstructure. Most of the other stereological quantities are much less sensitive to changes of microstructural geometry, they can not be assessed by simple counting, and they often require simplifying assumptions (particularly with respect to shape when 3D feature parameters are to be determined, and with respect to homogeneity when only single cross sections are available). In such cases stereological procedures are either very tedious or rather unreliable, and, whenever possible, should be substituted by other measurements, preferentially global stereological parameters or feature parameters measured by 3D microscopy.

3D microscopy, on the other hand, has its limits in that bulk samples can only be investigated up to a certain size (depending on the atomic number) and only to a modest resolution. When these limits are not critical, a wealth of information on each individual feature can be obtained. This means, however, that similarly to 2D image analysis, the large volume of data must be reduced to handy size. Correct and relevant averaging is not trivial, nor is the characterisation of complex geometric properties like shape, arrangement and distribution of feature parameters. With the predictable rapid development of instruments and techniques, statistical and mathematical procedures will be worked out. Let us hope that developers of 
these procedures will take a strong view on practical requirements and will avoid the accumulation of inadequate and redundant solutions.

\section{CONCLUSIONS}

It needs combination of the high creativity of scientists and the broad knowledge of the specialist to tackle practical problems of high technical or biological significance by measuring structural data. To do this in the most economic and effective way, 3D microscopy will certainly replace 2D image analysis as well as unreliable stereological procedures for important applications. Decisive advantages are that 3D microscopy does not damage the sample, that virtual (destruction free) cross sections are provided, and that the xyz coordinates are stored in the computer and can easily be further processed. Data processing procedures should be designed to provide relevant information only.

Some stereological procedures and related image analysis techniques are very useful, but others are obsolete, unduly laborious or even simply misleading, and many of the suggested applications for the more complex stereological methods are rather esoteric. However, when selectively optimised by using the few basic and some other relevant parameters, stereology will certainly not become redundant but in contrast remain or become the method of first choice.

It is fortunate that some recent conferences on image analysis are focussed on the application of stereological and related techniques rather than on the development of additional stereological techniques. To this author it seems obvious that application lags far behind the opportunities offered, and that the reason for this is the difficulty to select the suitable method out of the vast variety of methods developed. In order to avoid the confusion which prevails in 2D image analysis, publishing of new parameters and techniques should be kept to those which not only promise but have proven to be superior or at least adequate to the conventional ones for the intended application. It is also fortunate that theoreticians are cooperating closely with materials specialists. This may help to evaluate the theoretical concepts and to limit the publication to a relevant minimum in the future. This needs a lot of discipline on part of scientists in view of the untimely pressure to publish.

\section{ACKNOWLEDGMENT}

I dedicated this paper to my teacher Prof. Dr. Joseph Gurland, the outstanding pioneer in applying stereology to materials science, who died on December 23, 2003.

The preliminary form of this paper was originally presented at the $\mathrm{XI}^{\text {th }}$ International Congress for Stereology-Beijing Conference, Beijing, China, 4-8 November 2003.

\section{REFERENCES}

Bauer B, Exner HE (1981). Quantification and Reconstruction of Spatial Objects and Surfaces by Computer-aided Stereometry. Stereol Jugosl 3(Suppl. I):255-62.

Baruchel J, Boller E, Cloetens P, Ludwig W, Peyrin F (2000). Microtomography at a Third Generation Synchroton Radiation Facility. In: X-Ray Tomography in Materials Science. Paris: Hermes Science Publ., pp. 115-25.

Conan V, Gesbert S, Howard CV, Jeulin D, Meyer F, Renard D (1992). Geostatistical and Morphological Methods Applied to Three-Dimensional Microscopy. J Microsc 166(2):169-84.

Coster M, Chermant JL (1989). Précis d'Analyse d'Images. Paris: Editions du Centre National de la Recherche Scientifique.

Decker L, Jeulin D, Tovena I (1998). 3D Morphological Analysis of the Connectivity of a Porous Medium. Acta Stereol 17(1):107-12.

DeHoff RT, Rhines FN (1968). Quantitative Microscopy. New York: Mc Graw Hill Book Comp.

Delarue A, Jeulin D (2003). 3D Morphological Analysis of Composite Materials with Aggregates of Spherical Inclusions. Image Anal Stereol 22:153-61.

Durst K, Goeken M (2001). Quantitative Microstructural Characterization by Atomic Force Microscopy and Electron Microscopy - A Comparative Study on the Superalloy Waspaloy. Pract Metallogr 38:197-215.

Exner HE (1987). A Model Stereological Nomenclature. Acta Stereol 6(Suppl II):179-84.

Exner HE (1985). Scanning Electron Microscopy. In: Metals Handbook, $9^{\text {th }}$ Edition Vol 9. Metals Park: American Society for Metals, 89-102.

Exner HE (1992). Quantitative Description of Microstructural Geometry - A Practical Guide to Manual Processes. Pract Metallogr 30:216-25, 287-93, 322-33, 389-98.

Exner HE (1994). Quantitative Description of Microstructures by Image Analysis. In: Cahn RW et al., eds. Materials Science and Technology. Weinheim: VCH Publ., 281350 . 
Exner HE (1996). Qualitative and Quantitative Surface Microscopy. In: Physical Metallurgy, Amsterdam: Elsevier Science Publ., pp. 993-1032.

Exner HE (2001). Quantitative Metallography in Three Dimensions. Pract Metallogr 38:370-84.

Exner HE, Hougardy HP (1988). Quantitative Image Analysis of Microstructures. Oberursel: DGM Informationsgesellschaft-Verlag.

Exner HE, Rettenmayr M (1996). Quantitative Analysis of Microstructures and Materials Behaviour. Pract Metallogr 33:605-17.

Gratin L (1993). De la représentation des images au traitement morphologique d'images tridimensionnelles, Ph.D. Thesis, Paris: School of Mines.

Hilliard JE (1972). Stereology: An Experimental Viewpoint. In: Proceedings of the Symposium on Statistical and Probabilistic Problems in Metallurgy. Special Supplement to Advanced Applied Probabilities, 92-111.

Hornbogen E (1989). Fractals in Microstructure of Metals. Intern Mater Rev 34:277-305.

Hornbogen E (1991). Martensite and Metallography. Pract Metallogr 37:380-91.

Jaehne B (1993). Digital Image Processing - Concepts, Algorithms and Scientific Applications. Berlin: Springer Publ.

Maire E, Buffiere JY, Cloetens P, Ludwig W, Peix G (2002). High Resolution X-Ray Tomography Applied in the Observation of the Microstructure of Materials. Pract Metallogr 39:155-68.

Mandelbrot BB (1983). The Fractal Geometry of Nature. New York, San Francisco: W.H. Freeman \& Co.

Mandelbrot BB (1977). Fractals, Form, Chance and Dimension. San Francisco: W.H. Freeman \& Co.

Materna-Morris E, Lakota N, Merkel T, Muecke U, Scherer S, Walter M (2003). Comparison of Quantitative Fractography Methods. Pract Metallogr 40:273-86.

Ohser J (2001). Statistical Analysis of Microstructures - A Review of New Developments. Pract Metallogr 38: 151-68.

Ohser J, Muecklich F (2000). Statistical Analysis of Materials Structures. Chichester, N.Y.: J. Wiley \& Sons.

Pohl M (2001). Topological Quantification of Component Surfaces by Means of CLSM. Pract Metallogr 38:487-98.
Reckenwald T, Liu Z, Laurent T, Muecklich F (2003). A Quantitative Characterization of Periodic Surface Microstructures Induced by Laser Interference. Pract Metallogr 40:287-300.

Rhines FN (1986). Microstructology - Behaviour and Microstructure of Materials. Stuttgart: Dr. Riederer Verlag.

Russ JC (1986). Practical Stereology. New York: Plenum Press.

Russ JC (1990). Computer-Assisted Microscopy - The Measurement and Analysis of Images. New York: Plenum Press.

Saltykov SA (1974). Stereometrische Metallographie, Leipzig: VEB Deutscher Verlag für Grundstoffindustrie.

Schliffmann KI (2002). Scanning Probe Techniques in Material Science: Methods and Applications. Pract Metallogr 39:82-99.

Serra J (1982). Image Analysis and Mathematical Morphology. London: Academic Press.

Serra J (1988). Image Analysis and Mathematical Morphology. Vol. 2: Theoretical Advances. London: Academic Press.

Soille P (1999). Morphological Image Analysis. Berlin, Heidelberg: Springer Publ.

Stampfl J, Scherer S, Gruber M, Kolednik O (1996). Reconstruction of Surface Topographies by Scanning Electron Microscopy for Application in Fracture Research. Appl Physics A 63:341-6.

Underwood EE (1970). Quantitative Stereology. Reading: Addison-Wesley Publ. Comp.

Sauerwein C (2003). 3D-Computer-Tomographie: Anwendungsbeispiele aus der Praxis. Lecture Manuscript, Workshop on Image Analysis. Darmstadt: Fachhochschule.

Weibel ER (1980). Stereological Methods, Vol. 1: Practical Methods for Biological Morphometry, Vol. 2: Theoretical Foundations. London, New York, Toronto: Academic Press.

Wilson T (1990). Confocal Microscopy. San Diego: Academic Press.

Wojnar L (1999). Image Analysis - Applications in Materials Engineering. New York: CRC Press. 